\title{
Predictive value of CD4 cell count nadir on long-term mortality in HIV-positive patients in Uganda
}

This article was published in the following Dove Press journal:

HIVIAIDS - Research and Palliative Care

16 August 2012

Number of times this article has been viewed

\author{
Sarah Bray' \\ Jillian Gedeon' \\ Ahsan Hadi' \\ Ahmed Kotb' \\ Tarun Rahman' \\ Elaha Sarwar' \\ Anna Savelyeva' \\ Marika Sévigny' \\ Celestin Bakanda ${ }^{2}$ \\ Josephine Birungi ${ }^{2}$ \\ Keith Chan ${ }^{3}$ \\ Sanni Yaya' \\ Raywat Deonandan' \\ Edward J Mills ${ }^{1,2}$ \\ 'Interdisciplinary School of Health \\ Sciences, Faculty of Health Sciences, \\ University of Ottawa, Ottawa, Canada; \\ ${ }^{2}$ The AIDS Support Organization \\ (TASO), Headquarters, Kampala, \\ Uganda; ${ }^{3}$ British Columbia Centre \\ for Excellence in HIVIAIDS, Vancouver, \\ British Columbia, Canada
}

Correspondence: Edward J Mills

Faculty of Health Sciences, University of Ottawa, 35 University Private, Ottawa, Ontario, Canada KIN 7K4 Tel +l 7783178530

Email edward.mills@uottawa.ca
Objective: Although international guidelines recommend initiating antiretroviral therapy (ART) when a patient's CD4 cell count is $\leq 350$ cells $/ \mu \mathrm{L}$, most patients in resource-limited settings present with much lower CD4 cell counts. The lowest level that their CD4 cell count reaches, the nadir, may have long-term consequences in terms of mortality. We examined this health state in a large cohort of HIV+ patients in Uganda.

Design: This was an observational study of HIV patients in Uganda aged 14 years or older, who were enrolled in 10 major clinics across Uganda.

Methods: We assessed the CD4 nadir of patients, using their CD4 cell count at initiation of ART, stratified into categories $(<50,50-99,100-149,150-249,250+$ cells $/ \mu \mathrm{L})$. We constructed Kaplan-Meier curves to assess the differences in survivorship for patients left-censored at 1 year and 2 years after treatment initiation. We used Cox proportional hazards regression to model the associations between CD4 nadir and mortality. We adjusted mortality for loss-to-follow-up.

Results: Of 22,315 patients, 20,129 patients had greater than 1 year of treatment follow-up. Among these patients, 327 (1.6\%) died and 444 (2.2\%) were lost to follow-up. After leftcensoring at one year, relative to lowest CD4 strata, patients with higher CD4 counts had significantly lower rates of mortality (CD4 150-249, hazard ratio [HR] 0.60, 95\% confidence interval [CI]: $0.45-0.82, P=0.001 ; 250+$, HR $0.66,95 \%$ CI, $0.44-1.00, P=-0.05)$. Male sex, older age, and duration of time on ART were independently associated with mortality. When left-censoring at 2 years, CD4 nadir was no longer statistically significantly associated with mortality.

Conclusion: After surviving for 1 year on ART, a CD4 nadir was strongly predictive of longerterm mortality among patients in Uganda. This should argue for efforts to increase engagement with patients to ensure a higher CD4 nadir at initiation of treatment.

Keywords: antiretroviral therapy, ART, CD4, prognosis, sub-Saharan Africa

\section{Introduction}

CD4 T-cell status is a strong prognostic indicator of mortality and disease progression among individuals infected with HIV. ${ }^{1-3}$ CD4 cell status strongly correlates with World Health Organization (WHO) disease staging. ${ }^{4}$ Ascertaining CD4 status is now recommended as guidance for determining when to begin patients on antiretroviral therapy (ART). ${ }^{5}$ In 2010, WHO issued guidance to resource-constrained settings to expand the eligibility of the treated population, by recommending initiation of ART when a patient's CD4 T-cell count reached $350 / \mu \mathrm{L}$ or less, or was clinically necessitated. ${ }^{6}$ Most countries in resource-limited settings aim to deliver care at $\leq 350$ cells, yet the average CD4 cell count that patients actually initiate therapy at, is typically well below 200 cells $/ \mu \mathrm{L}$. 
Although patients who survive the initial period of most severe disease and possible immune reconstitution inflammatory syndrome are expected to have a nearly normal life after initiation of ART, ${ }^{8-10}$ progressive damage to a patient's immune system that occurred prior to accessing ART may have an important long-term effect on mortality. Many clinicians recognize the risk of increased mortality among patients with low CD4 status in the first several months of ART, but whether a low CD4 nadir (the lowest point a CD4 count achieves) is predictive of mortality after stabilization on ART is less clear. In 1999, an early EUROSida study demonstrated the importance of CD4 nadir in predicting longer-term negative outcomes. ${ }^{11}$ However, a larger study from North America and Europe using the Antiretroviral Cohort Collaboration (ART-CC) showed that mortality among patients with differing $\mathrm{CD} 4$ nadirs made no significant difference once a patient stabilized. ${ }^{10} \mathrm{~A}$ study we previously conducted in Uganda found that after 6 months on ART, patients with lower baseline CD4 counts had significantly worse outcomes than patients whose baseline count was higher. ${ }^{12}$ We aimed to examine mortality after longer periods of ART treatment and examined differences between patients after 1 and 2 years on treatment.

\section{Methods}

\section{Setting}

Our study used data collected by The AIDS Support Organization (TASO). TASO provides clinical care, psychosocial support, and antiretroviral therapy to individuals with HIV at 11 major clinical sites and 35 smaller clinics throughout Uganda, involving both urban and rural populations. TASO began providing widespread combination antiretroviral therapy in 2004 with resource support from the US President's Emergency Plan for AIDS Relief, and more than 24,000 patients are currently receiving this treatment. Criteria for initiation of antiretroviral therapy include a diagnosis of WHO stage 3 or 4 , or a CD4 cell count $<350$ cells $/ \mu \mathrm{L} .^{13}$ Patients initiating antiretroviral therapy typically receive a nonnucleoside reverse transcriptase inhibitor with first-line treatment comprising nevirapine, lamivudine, and stavudine; second-line therapy is comprised of boosted lopinavir, didanosine and zidovudine. ${ }^{14,15}$

\section{Cohort characteristics}

The cohort has been described in detail previously. ${ }^{16}$ Briefly, detailed demographic information, clinical characteristics, and treatment information are routinely collected on standardized forms at each patient visit. These data are entered into a centralized clinical database at each clinic. Upon enrolment at TASO, each patient is provided with a unique coded identification number. For this study, we included all patients $\geq 14$ years of age who initiated antiretroviral therapy at TASO clinics in Uganda between January 1, 2000 and February 1, 2010. Patients were followed until either time of confirmed death or end of the study period (February 1, 2010). The following pertinent patient information was recorded: age at the start of antiretroviral therapy, sex, CD4 count history, WHO clinical disease stage, loss from follow-up (a 3-month absence from a clinic), date of last visit, and date of death (where applicable).

\section{Analysis}

We used parametric testing to assess differences between patient clinical status and demographics among patients receiving less than or more than, 1 year of treatment. We considered patients' lowest monitored CD4 count to be their nadir. We stratified patients' $\mathrm{CD} 4$ nadirs according to the following categories $<50,50-99,100-149,150-249$, $250+$ cells $/ \mu \mathrm{L}$. We then calculated survival probabilities based on the CD4 nadir and date of death using a KaplanMeier plot for both the 1 year and 2 year periods postinitiation and compared these using the log-rank test. Patients who were lost to follow-up were censored at the date they were last seen at the clinic, and a weighted analysis was applied, whereby $30 \%$ of patients lost to follow-up were assumed dead, weighted by lower CD4, age, and male sex. ${ }^{17,18}$ Survival times were expressed in months. We used unadjusted and adjusted Cox proportional hazards regressions to express the magnitude of association between CD4 nadir and the probability of survival after 1 year of ART, while adjusting for age, sex, and WHO clinical disease stage. ${ }^{19}$ Hazard proportionality was assessed by analysis of scaled Schoenfeld residuals. To compensate for missing baseline CD4 nadirs, we conducted analyses using the multiple imputation method. ${ }^{20}$ All significance tests were two-sided with a $P$-value of $<0.05$. All analyses were conducted using SAS software (version 8; SAS Institute, Cary, NC).

\section{Institutional review}

Approval to conduct this study was received from the administrative headquarters ethics board of TASO Uganda, and the Research Ethics Boards of the University of Ottawa and the University of British Columbia in Canada. 


\section{Results}

\section{Patient demographics}

Of the 22,315 patients $\geq 14$ years of age in the TASO program between 2000 and 2010, 20,129 (90.2\%) patients had 1 or more years of follow-up and were included in this study. Their characteristics are summarized in Table 1 . Patients were followed for a median period of 33 months (Interquartile range [IQR], 23-47) and the majority, 70.3\%, were female. The median patient age was 37 years (IQR, 31-43) and the median CD4 cell count was 147 cells $/ \mu \mathrm{L}$ (IQR, 77-209) with 71.4\% of patients having CD4 cell counts below 200 cells $/ \mu \mathrm{L}$ at the initiation of treatment. Most patients, $56.3 \%$ and $33.3 \%$ were classified into WHO disease stage II or III, respectively.

\section{Mortality}

The majority of deaths (78\%) occurred in the first year of treatment and were therefore excluded from our survival analyses. Of patients with $>1$ year of follow up, 327 of patients died (1.6\%) and 444 patients $(2.2 \%)$ were lost to follow-up. Figure 1 shows a Kaplan-Meier graph that projects the survival of patients on ART with $>1$ year of follow-up, with different baseline CD4 cell count ranges. Baseline CD4 counts of 200-249 cells/ $\mu \mathrm{L}$ proved to be the best initial count for a higher probability of survival (HR $0.60,95 \%$ CI: $0.45-0.82, P=0.001)$. This was no longer statistically significant after left-censoring for 2 years of treatment (Figure 2).

\section{Regression analysis}

Table 2 displays the unadjusted and adjusted Cox proportional hazard models for patients with 1 or more years of follow-up. The adjusted model indicates that relative to the lowest CD4 strata, CD4 cell count nadir is independently associated with mortality. Male sex and older age are also important predictors of mortality.

Table I Characteristics of included patients

\begin{tabular}{|c|c|c|c|c|c|}
\hline Characteristics & Category & Total & $\begin{array}{l}<\mathbf{l} \text { year } \\
\text { n (\%) }\end{array}$ & $\begin{array}{l}\text { I+ years } \\
\text { n (\%) }\end{array}$ & $P$-value \\
\hline \multirow[t]{6}{*}{ Age } & $14-19$ & 333 & $35(1.6)$ & $298(1.5)$ & $<0.001$ \\
\hline & $20-29$ & 3486 & 409 (18.7) & 3077 (15.3) & \\
\hline & $30-39$ & 9774 & $967(44.2)$ & 8807 (43.8) & \\
\hline & $40-49$ & 6292 & $527(24.1)$ & $5765(28.6)$ & \\
\hline & $50+$ & 2430 & $248(11.3)$ & $2182(10.8)$ & \\
\hline & Total (n) & 22315 & 2186 & 20129 & \\
\hline \multirow[t]{3}{*}{ Sex } & Female & 15492 & $1347(6 \mid .6)$ & I4I45 (70.3) & $<0.001$ \\
\hline & Male & 6823 & $839(38.4)$ & 5984 (29.7) & \\
\hline & Total (n) & 22315 & 2186 & 20129 & \\
\hline \multirow[t]{8}{*}{$C D 4^{a}$} & $0-49$ & 3452 & 65I (37.5) & 2801 (16.7) & $<0.001$ \\
\hline & 050-99 & 2942 & $295(17)$ & $2647(15.8)$ & \\
\hline & $100-149$ & 3410 & $267(15.4)$ & $3143(18.8)$ & \\
\hline & $150-199$ & 3597 & $222(12.8)$ & $3375(20.1)$ & \\
\hline & $200-249$ & 2143 & $134(7.7)$ & $2009(12)$ & \\
\hline & $250-299$ & 874 & $47(2.7)$ & 827 (4.9) & \\
\hline & $300+$ & 2080 & $12 \mid(7)$ & 1959 (11.7) & \\
\hline & Total (n) & 18498 & 1737 & $|676|$ & \\
\hline \multirow[t]{5}{*}{ WHO Stage at ART initiation } & Stage I & 465 & $23(1.7)$ & $442(3.3)$ & $<0.001$ \\
\hline & Stage 2 & 7985 & $510(37.3)$ & $7475(56.3)$ & \\
\hline & Stage 3 & 4982 & $564(4 \mid .2)$ & $4418(33.3)$ & \\
\hline & Stage 4 & 1220 & $271(19.8)$ & $949(7.1)$ & \\
\hline & Total (n) & 14652 & 1368 & 13284 & \\
\hline \multirow[t]{3}{*}{ Death } & No & 20817 & $1015(46.4)$ & $19802(98.4)$ & $<0.001$ \\
\hline & Yes & 1498 & $|I 7|(53.6)$ & $327(1.6)$ & \\
\hline & Total (n) & 22315 & 2186 & 20129 & \\
\hline \multirow[t]{3}{*}{ Lost to follow-up } & No & 20882 & II $97(54.8)$ & I $9685(97.8)$ & $<0.001$ \\
\hline & Yes & 1433 & $989(45.2)$ & $444(2.2)$ & \\
\hline & Total (n) & 22315 & 2186 & 20129 & \\
\hline
\end{tabular}

Notes: Year = year of treatment; $P$-values indicate statistical differences in parametric tests between patients with less than I year of treatment and those with more than I year; ${ }^{a}$ cells/ $\mu \mathrm{L}$.

Abbreviations: WHO, World Health Organization; ART, antiretroviral therapy. 


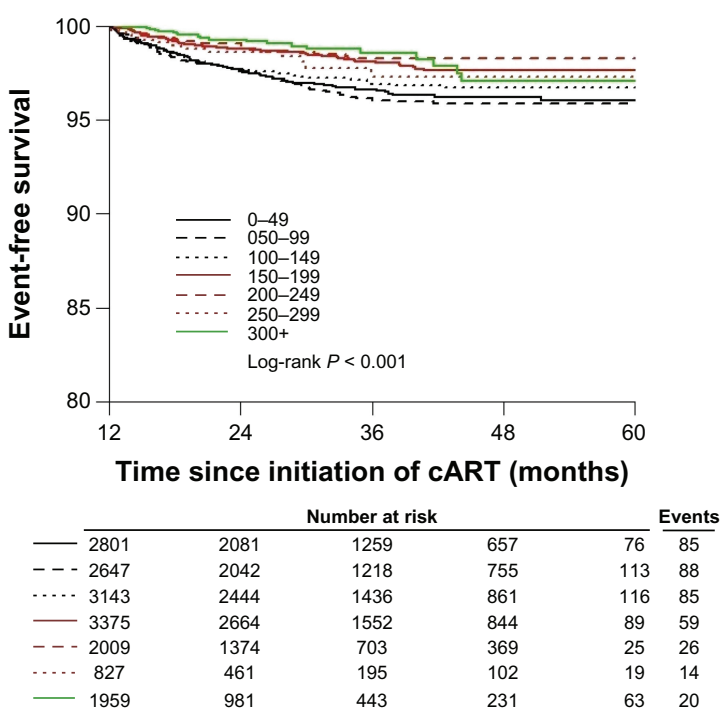

Figure I Kaplan-Meier probability plot of mortality for patients left-censored beginning I year after initiation of ART.

Abbreviations: ART, antiretroviral therapy; CART, combined antiretroviral therapy.

\section{Discussion}

Our study examined the prognostic value of CD4 nadir after 1 and 2 years of ART in HIV-infected patients in Uganda. Our study demonstrates that after 1 year on ART, a CD4 nadir continues to strongly predict mortality. Among patients who have survived 2 years on ART, CD4 nadir was no longer statistically significant. The reasons for death after stabilization on ART are poorly understood in resource-limited settings, but are not limited to occurrence of AIDS and may include

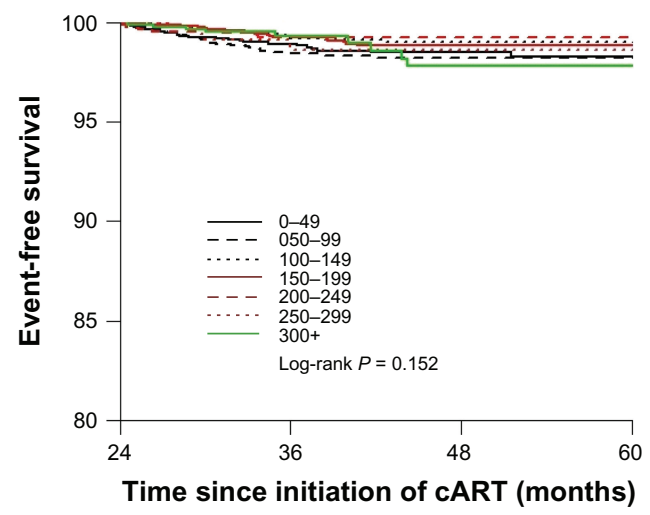

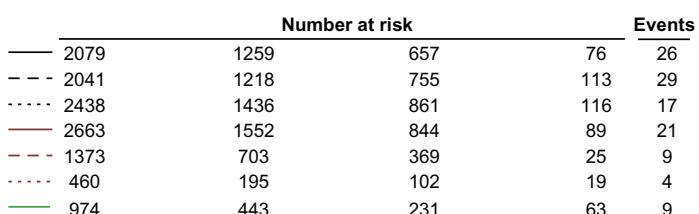

Figure 2 Kaplan-Meier probability plot of mortality for patients left-censored beginning 2 years after initiation of ART.

Abbreviations: ART, antiretroviral therapy; cART, combined antiretroviral therapy. early presentation of chronic diseases, exacerbated by HIV infection.

Strengths of our analysis include our nationally representative sample that comprised a diverse population of patients likely to be found in other parts of Africa, such as adolescents and elderly patients, patients suffering from conflict and food insecurity, and patients who switched treatment after initiation. Our loss of patients from follow-up was low compared with most AIDS service organizations in Africa, where loss to follow-up can exceed $50 \%^{21,22}$ due to our use of default tracers. Nevertheless, we recognized that there may have been misclassification of deaths among those lost to follow-up and we attempted to correct for this bias by applying an assumption that $30 \%$ of these patients were deceased, based on findings from our own previous tracking study, and a similar analysis at a relevant local Ugandan setting. ${ }^{18,23}$ We further weighted this assumption, to reflect older patients and those with lower last CD4 counts. ${ }^{24}$ The fact that our analysis includes a relatively small number of patients initiating therapy at high CD4 levels $(>350$ cells $/ \mu \mathrm{L})$ will likely have reduced our estimates at the very highest CD4 baseline status. About 10\% of individuals did not have baseline CD4 evaluations. This is common in programs across Africa, where patients may be initiated due to clinical circumstances or poor laboratory infrastructure. We explored the impact of these individuals on our overall analysis and did not find a different effect. We imputed their probable CD4 nadirs. TASO does not conduct routine viral load assessments and therefore we cannot make inferences about risks of nadir on viral load status. Finally, as with any observational study, our mortality rate may be subject to residual confounding beyond those confounders adjusted for in multivariate analysis.

Our findings are an extension of a previous analysis where we examined mortality in patients who survived the first 6 months on treatment. That study indicated that baseline CD4 was predictive of mortality even after survival for 6 months. ${ }^{12}$ Our current study displayed that the CD4 nadir was predictive of mortality among those with at least 1 year of treatment but not more than 2 years of treatment. This finding is not surprising as we would expect that patients who have survived greater than 2 years would have a better long-term expected survival rate than those at the early stages of treatment, as these patients have survived the period where most death occurs (ie, the first few months of therapy $)^{25}$ and are more likely to have adjusted to treatment in terms of adherence patterns and involvement with treatment supporters. ${ }^{26,27}$ 
Table 2 Unadjusted and adjusted Cox proportional hazard models of patients with I+ years follow up (with assumption that $30 \%$ of lost to follow-up were deaths)

\begin{tabular}{|c|c|c|c|c|}
\hline Variable & $\begin{array}{l}\text { Unadjusted } \\
\text { hazard } \\
\text { ratio }(95 \% \mathrm{Cl})\end{array}$ & $P$-value & $\begin{array}{l}\text { Adjusted } \\
\text { hazard } \\
\text { ratio }(95 \% \mathrm{Cl})\end{array}$ & $P$-value \\
\hline Age & & 0.494 & & \\
\hline $14-19$ & $0.76(0.35-1.65)$ & 0.001 & $0.84(0.39-1.83)$ & 0.660 \\
\hline $20-29$ & $0.56(0.40-0.79)$ & $<0.001$ & $0.68(0.48-0.96)$ & 0.028 \\
\hline $30-39$ & $0.58(0.44-0.76)$ & 0.005 & $0.61(0.46-0.80)$ & $<0.001$ \\
\hline $40-49$ & $0.67(0.50-0.88)$ & & $0.66(0.49-0.87)$ & 0.003 \\
\hline $50+$ & 1.00 & & 1.00 & \\
\hline Male sex & $1.60(1.32-1.93)$ & $<0.00$ I & $1.62(1.34-1.97)$ & $<0.00$ I \\
\hline \multicolumn{5}{|c|}{ CD4 at ART initiation } \\
\hline$<50^{\mathrm{a}}$ & 1.00 & & 1.00 & \\
\hline $50-99^{a}$ & $1.04(0.78-1.39)$ & 0.796 & $0.99(0.74-1.33)$ & 0.965 \\
\hline $100-149^{a}$ & $0.85(0.64-1.15)$ & 0.297 & $0.85(0.64-1.14)$ & 0.287 \\
\hline $150-249^{a}$ & $0.55(0.4 I-0.75)$ & $<0.001$ & $0.60(0.45-0.82)$ & 0.001 \\
\hline $250+^{a}$ & $0.56(0.36-0.88)$ & 0.014 & $0.66(0.44-1.00)$ & 0.051 \\
\hline \multicolumn{5}{|c|}{ WHO at ART initiation } \\
\hline Stage I & 1.00 & & 1.00 & \\
\hline Stage 2 & $0.65(0.43-0.98)$ & 0.038 & $0.80(0.54-1.20)$ & 0.279 \\
\hline Stage 3 & $0.91(0.55-1.5 \mathrm{I})$ & 0.707 & $0.97(0.59-1.61)$ & 0.906 \\
\hline Stage 4 & $0.92(0.47-1.79)$ & 0.796 & $1.13(0.58-2.21)$ & 0.699 \\
\hline $\begin{array}{l}\text { Year of } \\
\text { first cART }\end{array}$ & $0.55(0.5 \mathrm{I}-0.60)$ & $<0.001$ & $0.62(0.58-0.66)$ & $<0.00$ I \\
\hline
\end{tabular}

Note: ${ }^{\mathrm{a}}$ cells $/ \mu \mathrm{L}$.

Abbreviations: ART, antiretroviral therapy; WHO, World Health Organization; CART, combination antiretroviral therapy.

Consistent with previous studies from Africa, we found that mortality varied according to sex. This finding builds on an emerging body of literature displaying consistent shortcomings in treatment programs involving men. Men are less likely to access antiretroviral treatment, usually will start treatment with more advanced disease, have higher rates of early mortality, and are more likely to be lost to follow-up..$^{28-30}$

Unfortunately, accessing and treating patients at early stages can be a challenge for both health infrastructure, and identifying patients. In Uganda, the ministry of health guidelines recommend treatment of patients with ART when a CD4 nadir reaches below $<350$ cells $/ \mu \mathrm{L}^{13}$ and yet the median CD4 of patients initiating treatment within our cohort in 2009 was far lower, at 156 cells $/ \mu \mathrm{L}$. There is a clear need to increase the identification of infected individuals while their CD4 status is high so that they can be engaged in care and treatment initiated as early as possible. Strategies to engage patients at an early stage include home-based testing campaigns and campaigns targeting specific groups, including men. ${ }^{31,32}$ Residual benefits of increasing early access to ART include economic benefits, increased life expectancy, and a decreased likelihood of transmission of the virus to sexual partners. ${ }^{33,34}$
In conclusion, our study demonstrates that in Uganda, a patient's CD4 nadir is strongly predictive of longer-term mortality even after 1 year of treatment. Efforts to increase access to care for patients before their immune status becomes depleted continue to represent an important challenge that has long-term repercussions for patients.

\section{Acknowledgments}

The Canadian Institutes of Health Research (CIHR) funded this study. TASO receives core funding from the US Presidents Emergency Plan for AIDS Relief.

\section{Disclosure}

The authors declare no conflicts of interest in this work.

\section{References}

1. Hogg RS, Yip B, Chan KJ, et al. Rates of disease progression by baseline CD4 cell count and viral load after initiating triple-drug therapy. JAMA. 2001;286(20):2568-2577.

2. Sterne JA, May M, Costagliola D, et al; for When To Start Consortium Timing of initiation of antiretroviral therapy in AIDS-free HIV-1infected patients: a collaborative analysis of 18 HIV cohort studies. Lancet. 2009;373(9672):1352-1363.

3. Kitahata MM, Gange SJ, Abraham AG, et al; for NA-ACCORD Investigators. Effect of early versus deferred antiretroviral therapy for HIV on survival. N Eng J Med. 2009;360(18):1815-1826.

4. World Health Organization. WHO Case Definitions of HIV for Surveillance and Revised Clinical Staging and Immunological Classification of HIV-Related Disease in Adults and Children; 2007. Available from: http://www.who.int/hiv/pub/vct/hivstaging/en/index.html Accessed June 10, 2012

5. Thompson MA, Aberg JA, Cahn P, et al; for International AIDS Society-USA. Antiretroviral treatment of adult HIV infection: 2010 recommendations of the International AIDS Society-USA panel. JAMA 2010;304(3):321-333

6. WHO. Antiretroviral therapy for HIV infection in adults and adolescents Recommendations for a public health approach: 2010 revision. Available at http://www.who.int/hiv/pub/arv/adult2010/en/. 2010. Accessed June 14, 2012.

7. Keiser O, Tweya H, Braitstein P, et al; for ART-LINC of IeDEA Study Group. Mortality after failure of antiretroviral therapy in sub-Saharan Africa. Trop Med Int Health. 2010;15(2):251-258.

8. Mills E, Bakanda C, Birungi J, et al. Life expectancy of persons receiving combination antiretroviral therapy in low-income countries: a cohort analysis from Uganda. Ann Intern Med. 2011;155(4):209-216.

9. Jaffe HW, De Stavola BL, Carpenter LM, Porter K, Cox DR; for CASCADE Collaboration. Immune reconstitution and risk of Kaposi sarcoma and non-Hodgkin lymphoma in HIV-infected adults. Aids. 2011;25(11):1395-1403.

10. Chêne G, Sterne JA, May M, et al; for Antiretroviral Therapy Cohort Collaboration. Prognostic importance of initial response in HIV-1 infected patients starting potent antiretroviral therapy: analysis of prospective studies. Lancet. 2003;362(9385):679-686.

11. Miller V, Mocroft A, Reiss P, et al. Relations among CD4 lymphocyte count nadir, antiretroviral therapy, and HIV-1 disease progression: results from the EuroSIDA study. Ann Intern Med. 1999;130(7): 570-577.

12. Mills EJ, Bakanda C, Birungi J, Yaya S, Ford N; for the TASO-CAN Writing Group. The prognostic value of baseline CD4 cell count beyond 6 months of antiretroviral therapy in HIV-positive patients in a resourcelimited setting. Aids. 2012;26(11):1425-1429. 
13. Ministry of Health. National Antiretroviral Treatment and Care Guidelines for Adults and Children. Kampala, Uganda: Earnest Publishers; 2010.

14. Mills EJ, Bakanda C, Birungi J, Yaya S, Ford N. The prognostic value of baseline CD4 cell count beyond 6 months of antiretroviral therapy in a resource-limited setting. Aids. 2012;26(11):1425-1429.

15. Kiboneka A, Nyatia R, Nabiryo C, et al. Combination antiretroviral therapy in population affected by conflict: outcomes from large cohort in northern Uganda. BMJ. 2009;338:b201.

16. Bakanda C, Birungi J, Nkoyooyo A, et al. Cohort Profile: The TASOCAN Cohort Collaboration. Int J Epidemiol. March 7, 2011. [Epub ahead of print.]

17. Geng EH, Emenyonu N, Bwana MB, Glidden DV, Martin JN. Sampling-based approach to determining outcomes of patients lost to follow-up in antiretroviral therapy scale-up programs in Africa. JAMA. 2008;300(5):506-507.

18. Amuron B, Namara G, Birungi J, et al. Mortality and loss-to-follow-up during the pre-treatment period in an antiretroviral therapy programme under normal health service conditions in Uganda. BMC Public Health. 2009;9:290.

19. Allison PD. Survival Analysis Using SAS: A Practical Guide. Cary, NC: SAS Institute Inc; 1995.

20. Yuan YC. Multiple Imputation for Missing Data: Concepts and New Development (Version 9.0). Available from http://analysis3. com/Multiple-Imputation-for-Missing-Data-Concepts-and-NewDevelopment-pdf-e4976.pdf. Accessed July 15, 2012.

21. Rosen S, Fox MP, Gill CJ. Patient retention in antiretorviral therapy programs in sub-Sarahan Africa: a systematic review. PLoS Med. 2007;4(10):e298.

22. Brinkhof MW, Pujades-Rodriguez M, Egger M. Mortality of patients lost to follow-up in antiretroviral treatment programmes in resourcelimited settings: systematic review and meta-analysis. PLoS One. 2009;4(46):e5790.

23. Geng EH, Emenyonu N, Bwana MB, Glidden DV, Martin JN. Sampling-based approach to determining outcomes of patients lost to follow-up in antiretroviral therapy scale-up programs in Africa. JAMA. 2008;300(5):506-507.

24. Egger M, Spycher B, Sidle J, et al. Correcting mortality for loss to follow up: a graphical approach applied to art programmes in resource-limited settings. 5th IAS Conference on HIV Pathogenesis, Treatment and prevention, July 19-22, 2009, Cape Town, South Africa. Poster \#WEPED173.
25. Braitstein P, Brinkhof MW, Dabis F, et al; for Anteretroviral Therapy in Lower Income Countries (ART-LINC Collaboration; ART Cohort Collaboration (ART-CC) groups. Mortality of HIV-1-infected patients in the first year of antiretroviral therapy: comparison between low-income and high-income countries. Lancet. 2006;367(9513):817-824.

26. Ford N, Darder M, Spelman T, Maclean E, Mills E, Boulle A. Early adherence to antiretroviral medication as a predictor of long-term HIV virological suppression: five-year follow up of an observational cohort. PLoS One. 2010;5(5):e10460.

27. Chang LW, Kagaayi J, Nakigozi G, et al. Effect of peer health workers on AIDS care in Rakai, Uganda: a cluster-randomized trial. PLoS One. 2010;5(6):e10923.

28. Braitstein P, Boulle A, Nash D, et al; for Antiretroviral Therapy in Lower Income Countries (ART-LINC) study group. Gender and the use of antiretroviral treatment in resource-constrained settings: findings from a multcenter collaboration. $J$ Womens Health (Larchmt). 2008;17(1):47-55.

29. Muula AS, Ngulube TJ, Siziya S, et al. Gender distribution of adult patients on highly active antiretroviral therapy (HAART) in Southern Africa: a systematic review. BMC Public Health. 2007;7:63.

30. Mills EJ, Ford N, Mugyenyi P. Expanding HIV care in Africa: making men matter. Lancet. 2009;374(9686):275-276.

31. Wachira J, Kimaiyo S, Ndege S, Mamlin J, Braitstein P. What is the impact of home-based HIV counseling and testing on the clinical status of newly enrolled adults in a large HIV care program in Western Kenya? Clin Infect Dis. 2012;54(2):275-281.

32. Braitstein P, Boulle A, Nash D, et al; for Antiretroviral Therapy in Lower Income Countries (ART-LINC) study group. Gender and the use of antiretroviral treatment in resource-constrained settings: findings from a multicenter collaboration. $J$ Womens Health (Larchmt). 2008;17(1):47-55.

33. Cohen MS, Chen YQ, McCauley M, et al; for HPTN 052 Study Team. Prevention of HIV-1 infection with early antiretroviral therapy. $N$ Engl J Med. 2011;365(6):493-505.

34. Larson BA, Fox MP, Rosen S, et al. Do the socioeconomic impacts of antiretroviral therapy vary by gender? A longitudinal study of Kenyan agricultural worker employment outcomes. BMC Public Health. 2009;9:240
HIV/AIDS - Research and Palliative Care

\section{Publish your work in this journal}

HIV/AIDS - Research and Palliative Care is an international, peerreviewed open-access journal focusing on advances in research in HIV, its clinical progression and management options including antiviral treatment, palliative care and public healthcare policies to control viral spread. The journal welcomes original research, basic science,

\section{Dovepress}

clinical \& epidemiological studies, reviews \& evaluations, expert opinion \& commentary, case reports \& extended reports. The manuscript management system is completely online and includes a very quick and fair peer-review system. Visit http://www.dovepress.com/ testimonials.php to read real quotes from published authors. 